\title{
An evolving spectrum of diabetes in a woman with GCK-MODY
}

\author{
Aoife Garrahy, Matilde Bettina Mijares Zamuner and Maria M Byrne
}

\section{Summary}

Coexistence of autoimmune diabetes and maturity-onset diabetes of the young (MODY) is rare. We report the first case of coexisting latent autoimmune diabetes of adulthood (LADA) and glucokinase (GCK) MODY. A 32-year-old woman was treated with insulin for gestational diabetes at age 32 years; post-partum, her fasting blood glucose was $6.0 \mathrm{mmol} / \mathrm{L}$ and 2-h glucose was $11.8 \mathrm{mmol} / \mathrm{L}$ following an oral glucose tolerance test, and she was maintained on diet alone. Five years later, a diagnosis of LADA was made when she presented with fasting blood glucose of $20.3 \mathrm{mmol} / \mathrm{L}$ and HbA1C $125 \mathrm{mmol} /$ mol (13.6\%). GCK-MODY was identified 14 years later when genetic testing was prompted by identification of a mutation in her cousin. Despite multiple daily insulin injections her glycaemic control remained above target and her clinical course has been complicated by multiple episodes of hypoglycaemia with unawareness. Although rare, coexistence of latent autoimmune diabetes of adulthood and monogenic diabetes should be considered if there is a strong clinical suspicion, for example, family history. Hypoglycaemic unawareness developed secondary to frequent episodes of hypoglycaemia using standard glycaemic targets for LADA. This case highlights the importance of setting fasting glucose targets within the expected range for GCK-MODY in subjects with coexisting LADA.

\section{Learning points:}

- We report the first case of coexisting latent autoimmune diabetes of adulthood (LADA) and GCK-MODY.

- It has been suggested that mutations in GCK may lead to altered counter-regulation and recognition of hypoglycaemia at higher blood glucose levels than patients without such mutation. However, in our case, hypoglycaemic unawareness developed secondary to frequent episodes of hypoglycaemia using standard glycaemic targets for LADA.

- This case highlights the importance of setting fasting glucose targets within the expected range for GCK-MODY in subjects with coexisting LADA to avoid hypoglycaemia.

\section{Background}

Maturity-onset diabetes of the young (MODY) is a form of genetic diabetes that is inherited in an autosomal dominant fashion. Inactivating mutations in the glucokinase (GCK) gene account for approximately $30 \%$ of cases and result in a higher threshold for glucose-stimulated insulin secretion manifest as mild stable fasting hyperglycaemia. A concurrent diagnosis of autoimmune diabetes is rare, with only four cases previously reported in the literature - in all cases, diabetes was diagnosed in childhood
$(1,2,3,4)$. Because glucokinase is not only expressed in the pancreatic beta-cell but also in alpha cells, hepatocytes and central nervous system, it has been suggested that mutations in GCK may affect counter-regulatory response to hypoglycaemia and lead to recognition of hypoglycaemia at higher blood glucose levels than people without such mutation (5). We report the case of a woman, age 32 years, with a history of gestational diabetes subsequently diagnosed with latent autoimmune 
diabetes of adulthood (LADA) at age 37 years in whom GCK-MODY was later identified when genetic testing was prompted by a positive family history.

\section{Case presentation}

A 32-year-old woman was noted to have glycosuria and was diagnosed with gestational diabetes at 19 weeks during her third pregnancy, in 1997. A $100 \mathrm{~g}$ oral glucose tolerance test showed time 0 blood glucose $6.1 \mathrm{mmol} / \mathrm{L}, 1 \mathrm{~h}$ $11.1 \mathrm{mmol} / \mathrm{L}, 2 \mathrm{~h} 8.3 \mathrm{mmol} / \mathrm{L}$ and $3 \mathrm{~h} 7.8 \mathrm{mmol} / \mathrm{L}$. She had two previous large babies $(4.5 \mathrm{~kg}$, 42 weeks gestation and $4.9 \mathrm{~kg}, 40$ weeks gestation). Family history was notable for gestational diabetes in her mother, and insulin-requiring diabetes in a cousin. She required insulin therapy from 26 weeks gestation and was noted to have multiple episodes of hypoglycaemia; corrected fructosamine was $249-295 \mathrm{mmol} / 70 \mathrm{~g}$ protein (normal range $205-285 \mathrm{mmol} / 70 \mathrm{~g}$ protein). She gave birth to a $3.8 \mathrm{~kg}$ baby girl at 39 weeks. An oral glucose tolerance test 6 weeks post-partum was diagnostic of diabetes (fasting blood glucose $6.0 \mathrm{mmol} / \mathrm{L}, 2 \mathrm{~h} 11.8 \mathrm{mmol} / \mathrm{L}$ ) and she was given dietary advice.

Five years later, in 2002, she presented to her general practitioner with candidiasis and glycosuria was noted. Fasting glucose level was $20.3 \mathrm{mmol} / \mathrm{L}, \mathrm{HbA} 1 \mathrm{C} 125 \mathrm{mmol} /$ mol $(13.6 \%)$ and she was re-referred to the diabetic services. Ketones were negative and she had no osmotic symptoms. She was commenced initially on gliclazide $60 \mathrm{mg}$ and metformin $500 \mathrm{mg}$ twice daily. Mixed insulin was added at 4 months due to osmotic symptoms and HbA1C of $93 \mathrm{mmol} / \mathrm{mol}$ (10.7\%). HbA1C improved to $77 \mathrm{mmol} / \mathrm{mol}(9.2 \%)$ after 3 months on insulin therapy. Hypertension and dyslipidaemia were treated.

\section{Investigation}

From 2002 to 2008, HbA1C failed to improve to target, average $73 \mathrm{mmol} / \mathrm{mol}(8.8 \%)$ on $44-62$ units of insulin per day (Fig. 1). Despite the high HbA1C, insulin therapy resulted in frequent episodes of hypoglycaemia of which she was unaware. Anti-GAD antibodies were positive $(44 \mu / \mathrm{mL})$ confirming a diagnosis of LADA; TPO antibodies were also positive and she was treated for hypothyroidism. Six years after commencing insulin, she was incidentally diagnosed with a phaeochromocytoma (6) which was resected and she declined genetic testing at that point.

Subsequently in 2016, the woman's cousin who was lean with NIDDM was diagnosed with GCK-MODY (c.478G>C, p.Asp160His) in our MODY clinic (Fig. 2). This prompted genetic testing in our case which revealed the same mutation. Fasting glucose (after holding evening Levemir) was $20.3 \mathrm{mmol} / \mathrm{L}$, ketones were negative, and she had detectable but low C-peptide levels at $52 \mathrm{pmol} / \mathrm{L}$ (RR 260-1730).

\section{Treatment}

A blinded iPro 2 continuous glucose monitor (Medtronic Inc.) was applied and the patient was asked to record

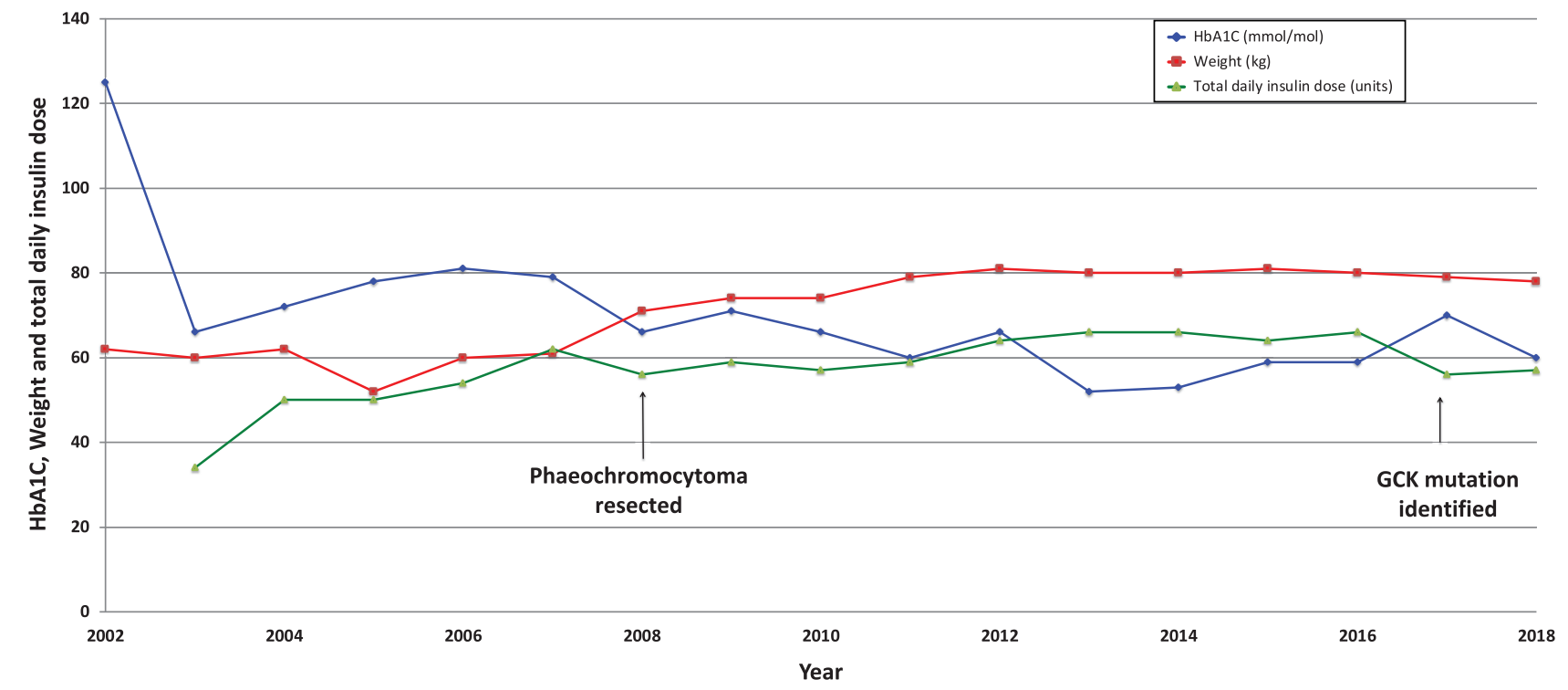

Figure 1

Trend in HbA1C, weight and total daily insulin dose from 2002 to 2018. 


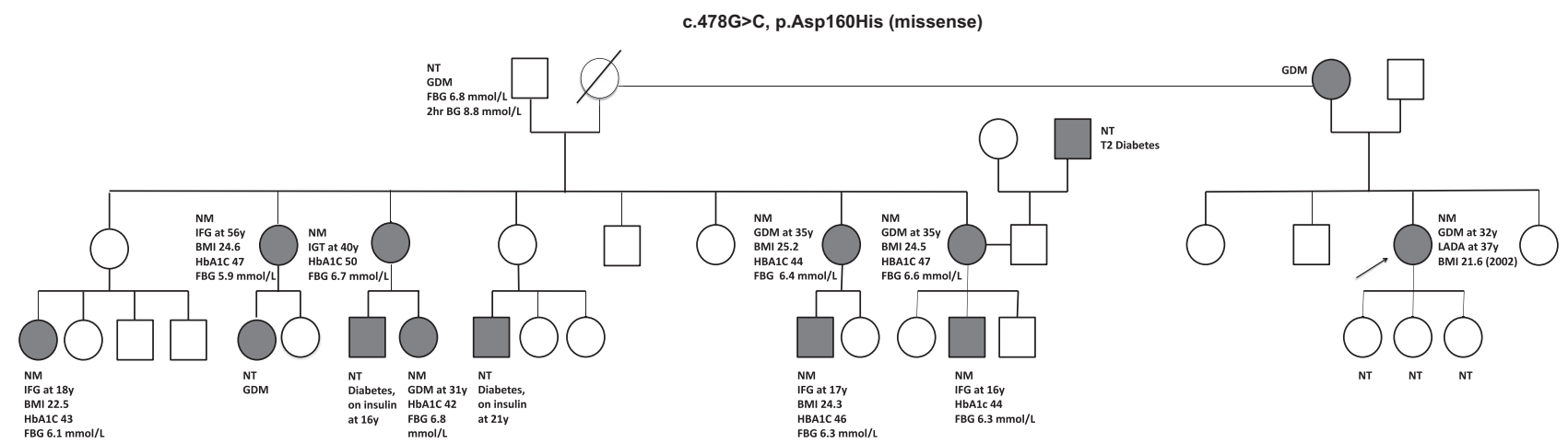

Figure 2

Pedigree illustrating GCK mutation positivity across two generations. The arrow indicates the proband. Squares denote male subjects, circles denote female subjects and a line through a symbol denotes deceased. Filled icons indicate individuals with known fasting hyperglycaemia (>5.5 mmol/L), GDM or overt diabetes. Clinical information is given beside the corresponding symbol. BMI, body mass index; FBG, fasting blood glucose; GDM, gestational diabetes; LADA, latent autoimmune diabetes of adulthood; NM, heterozygous for c.478G >C p.Asp160His (missense); NT, not tested. HbA1C units: mmol/mol.

her capillary blood glucose readings and document any symptoms of hypoglycaemia. On day two, the monitor detected an episode of hypoglycaemia $(2.2 \mathrm{mmol} / \mathrm{L})$ at 04:00h, which did not wake her until 06:00 h, and a second episode $(2.3 \mathrm{mmol} / \mathrm{L})$ at $19: 00 \mathrm{~h}$, with no symptoms. HBA1c at that time was $59 \mathrm{mmol} / \mathrm{L}$ and she reported hypo recognition at $2.2 \mathrm{mmol} / \mathrm{L}$. Insulin doses were reduced from total daily dose of 66 units to 54 units in an attempt to achieve glycaemic levels that would be found in untreated GCK-MODY that is targeting a fasting glucose of 7-8.0 mmol/L in this case.

\section{Outcome and follow-up}

Following a reduction in insulin doses, episodes of hypoglycaemia were significantly reduced on a second sensor, and the patient reported sensing hypoglycaemia at $3.7 \mathrm{mmol} / \mathrm{L}$; HBA1c was $70 \mathrm{mmol} / \mathrm{mol}$. Most recent urine albumin creatinine ratio is $3.2 \mathrm{~g} / \mathrm{mol}(<2.5)$. More recent HBA1c is $60 \mathrm{mmol} / \mathrm{L}$ with Levemir increased to 20 units (from 18 units) and she is sensing hypogylcaemia at $4 \mathrm{mmol} / \mathrm{L}$.

\section{Discussion}

Glucokinase $(G C K)$ catalyses the rate-limiting step of insulin secretion - glucose phosphorylation, thereby acting as the glucose sensor of the beta-cell. Heterozygous inactivating mutations in the gene encoding GCK reset the glucose threshold for insulin secretion by the pancreatic beta-cell to a higher level. This leads to mild fasting hyperglycaemia $(5.5-8.0 \mathrm{mmol} / \mathrm{L})$ which is often only detected later in life during screening for other reasons (7). The hyperglycaemia detected in GCK-MODY shows little deterioration with age and does not infer an increased risk of diabetes-related microvascular complications. HbA1C typically ranges from $38-56 \mathrm{mmol} / \mathrm{mol}(5.6-7.3 \%)$ in subjects $<40$ years and $41-60 \mathrm{mmol} / \mathrm{mol}(5.9-7.6 \%)$ in those aged $>40$ years. Oral hypoglycaemic agents or insulin rarely improve glycaemic control in GCK-MODY (8), and the general consensus is that the majority of these people do not require glucose-lowering treatment. Approximately 1-2\% of women with gestational diabetes have GCK-MODY; the diagnosis should be considered when fasting hyperglycaemia persists post-partum, particularly in the setting of normal BMI or a family history (5). In this case, the woman's post-partum OGTT demonstrated a rise in blood glucose of $5.8 \mathrm{mmol} / \mathrm{L}$ in response to an oral glucose load; this is a greater rise than typically seen in the majority of patients with GCKMODY ( $<3 \mathrm{mmol} / \mathrm{L})(5)$, and the test was interpreted as diagnostic of early type 2 diabetes at that time.

While detectable GAD antibodies have been reported in $1 \%$ of people with MODY, the majority of these are not associated with clinical manifestations of type 1 diabetes (2). The occurrence of overt autoimmune diabetes and GCK-MODY in the same person is exceedingly rare - to the best of our knowledge, this is the fifth published case. Genetic testing was only performed in our case following identification of the mutation in a family member who was referred to our specialist MODY clinic so it is likely that more cases remain unrecognised. In the four previous published cases, type 1 diabetes was diagnosed in childhood (age range $4-12$ years) $(1,2,3,4)$; therefore, this is the first case of coexisting LADA and GCK-MODY. The diagnosis of LADA is supported by an interval of 5 years between diabetes diagnosis and insulin dependence, positive GAD antibodies and low C-peptide levels. 
Aiming for typical type 1 diabetic targets in our case, including fasting blood glucose 4.4-7.2 mmol/L, with insulin therapy has resulted in episodes of hypoglycaemia, and this has been associated with weight gain.

As well as the pancreatic beta-cell, glucokinase is expressed in alpha cells, hepatocytes and the central nervous system (9). Therefore, inactivating mutations of GCK as seen in GCK-MODY may affect counterregulatory response to hypoglycaemia. In a recent hyperinsulinaemic glucose clamp study comparing people with GCK-MODY, type 2 diabetes and healthy controls, Chakera et al. demonstrated higher glycaemic thresholds for increasing glucose production and for glucagon and epinephrine, stimulation in people with GCK-MODY during progressive hypoglycaemia (10). It has been suggested that this higher set-point for counterregulatory response to hypoglycaemia may be secondary to decreased glucokinase activity in hypothalamic neuronal cells or alterations of glucose sensing in pancreatic alpha cells and liver cells (11). Uday et al. reported the case of a 14-year-old boy with coexisting GCK-MODY and type 1 diabetes in whom efforts to normalise blood glucose levels resulted in recurrent episodes of severe hypoglycaemia. After demonstrating nadir blood glucose of $5.5 \mathrm{mmol} / \mathrm{L}$ in the boy's father (diagnosed with GCK-MODY but not type 1 diabetes) with continuous glucose monitoring, they established a new threshold for treating hypoglycaemia $-5.5 \mathrm{mmol} / \mathrm{L}$. By treating hypoglycaemia below this setpoint, frequency of severe hypoglycaemic events was reduced and HbA1C gradually improved but did not reach the target of $<58 \mathrm{mmol} / \mathrm{L}(7.5 \%)$ as a consequence of coexisting MODY (3).

The theory that in people with coexisting type 1 diabetes, the use of higher doses of insulin to lower blood glucose levels to standard type 1 targets may lead to symptoms of hypoglycaemia at glucose levels typically considered to be within target has not been proven in our case. In the initial 2 years after commencing insulin therapy, the woman reported hypoglycaemic awareness at blood glucose of $3.6 \mathrm{mmol} / \mathrm{L}$ and following periods of recurring hypoglycaemia, her awareness of hypoglycaemia deteriorated. It is possible that her hypoglycaemic awareness declined with recurrent episodes of hypoglycaemia over a long duration. This difference in threshold for hypoglycaemia awareness from that seen in Guenat's study may be due to her coexisting autoimmune diabetes and a blunting of awareness resulting from recurring episodes of hypoglycaemia which do not occur in GCK-MODY patients in whom insulin treatment is not routinely recommended. Recurrent episodes of hypoglycaemia can occur by trying to achieve standard targets in these patients, hence highlighting the importance of diagnosing GCK-MODY. Revising the glycaemic targets to fasting blood glucose $7-8 \mathrm{mmol} / \mathrm{L}$ in this case have reduced the episodes of hypoglycaemia and stabilised her glucose control.

\section{Declaration of interest}

The authors declare that there is no conflict of interest that could be perceived as prejudicing the impartiality of the research reported.

\section{Funding}

This research did not receive any specific grant from any funding agency in the public, commercial or not-for-profit sector.

\section{Patient consent}

Written informed consent has been obtained from the patient prior to publication.

\section{Author contribution statement}

Dr Aoife Garrahy performed the literature review and constructed the manuscript. Dr Matilde Bettina Mijares Zamuner contributed to the manuscript and images. Dr Maria Byrne is the patient's diabetologist and she reviewed and edited the manuscript.

\section{References}

1 Maltoni G, Zucchini S, Scipione M, Mantovani V, Salardi S \& Cicognani A. Onset of type 1 diabetes mellitus in two patients with maturity onset diabetes of the young. Pediatric Diabetes 201213 208-212. (https://doi.org/10.1111/j.1399-5448.2011.00788.x)

2 McDonald TJ, Colclough K, Brown R, Shields B, Shepherd M, Bingley P, Williams A, Hattersley AT \& Ellard S. Islet autoantibodies can discriminate maturity-onset diabetes of the young (MODY) from type 1 diabetes. Diabetic Medicine 201128 1028-1033. (https://doi. org/10.1111/j.1464-5491.2011.03287.x)

3 Uday S, Campbell FM, Cropper J \& Shepherd M. Monogenic diabetes and type 1 diabetes mellitus: a challenging combination. Practical Diabetes 201431 327-330. (https://doi.org/10.1002/pdi.1896)

4 Calcaterra V, Martinetti M, Salina A, Aloi C \& Larizza D. The coexistence of type 1 diabetes, MODY2 and metabolic syndrome in a young girl. Acta Diabetologica 201249 401-404. (https://doi. org/10.1007/s00592-011-0300-2)

5 Chakera AJ, Steele AM, Gloyn AL, Shepherd MH, Shields B, Ellard S \& Hattersley AT. Recognition and management of individuals with hyperglycemia because of a heterozygous glucokinase mutation. Diabetes Care 201538 1383-1392. (https://doi.org/ 10.2337/dc14-2769)

6 Dolan RT, Butler JS, Mentee GP \& Byrne M. Pheochromocytoma presenting as recurrent urinary tract infections: a case report. Journal of Medical Case Reports 20115 6. (https://doi. org/10.1186/1752-1947-5-6)

7 Byrne MM, Sturis J, Clement K, Vionnet N, Pueyo ME, Stoffel M, Takeda J, Passa P, Cohen D, Bell GI, et al. Insulin secretory abnormalities in subjects with hyperglycemia due to glucokinase 
mutations. Journal of Clinical Investigation 199493 1120-1130. (https://doi.org/10.1172/JCI117064)

8 Hattersley AT \& Pearson ER. Minireview: pharmacogenetics and beyond: the interaction of therapeutic response, beta-cell physiology, and genetics in diabetes. Endocrinology 2006147 2657-2663. (https:// doi.org/10.1210/en.2006-0152)

9 De Backer I, Hussain SS, Bloom SR \& Gardiner JV. Insights into the role of neuronal glucokinase. American Journal of Physiology: Endocrinology and Metabolism 2016311 E42-E55. (https://doi. org/10.1152/ajpendo.00034.2016)
10 Chakera AJ, Hurst PS, Spyer G, Ogunnowo-Bada EO, Marsh WJ, Riches $\mathrm{CH}$, Yueh CY, Markkula SP, Dalley JW, Cox RD, et al. Molecular reductions in glucokinase activity increase counterregulatory responses to hypoglycemia in mice and humans with diabetes. Molecular Metabolism 201817 17-27. (https://doi. org/10.1016/j.molmet.2018.08.001)

11 Guenat E, Seematter G, Philippe J, Temler E, Jequier E \& Tappy L. Counterregulatory responses to hypoglycemia in patients with glucokinase gene mutations. Diabetes and Metabolism 200026 $377-384$.

Received in final form 1 December 2018

Accepted 11 December 2018 